\section{Considerações Gerais sobre a Viabilidade de Empreendimentos Hoteleiros}

\section{Ari Belli $^{1}$}

RESUMO: Apresenta uma série de observações relevantes percebidas pelo autor e que foram ou são negligenci adas por alguns empreendedores, projetistase analistas de projetona implantação ou expansão de empreendimentos hoteleiros. A não observância ou o desconhecimento de alguns itens vem causando sérias dificuldades para empreendedores e agentes financeiros que concederam financiamentos. Fatos que explicam, pelo menos em parte 0 alto índice de inadimplência que o setor apresenta perante os agentes financeiros atualmente.

PALAVRAS-CHAVE: Hotelaria; hotel; empreendimentos hoteleiros; projetos; análise de investimentos; viabilidade.

ABSTRACT: This paper presents a serial of observations that the authorperceives relevant and they wereneglected by some entrepreneurs, by projectists and by investiment analists in the implemention or in the expansion of hotel entreprises. The non observation or no knowledge of some items are making serious difficulties to entrepreneurs and for the banks that finance these hotels. These facts explain, at least inpart, the high index of the no payments of loans.

KEYWORDS: Hotel industry; hotel investiment analysis viability.

\section{Introduçāo}

Com o objetivo de otimizar resultados e relatar detalhes que foram percebidos nas fases de pesquisa e de teste do modelo de Análise Paramétrica de Empreendimentos Hoteleiros, fruto da Dissertação de Mestrado, colocam-se estas consideraçōes. Uma versão preliminar do referido modelo foi apresentada na revista Turismo em Análise (Belli et al., 1996:85-92). Adicionou-se ainda as observações obtidas no desempenho das funções de analista de projeto do Banco Regional de Desenvolvimento do Extremo Sul (BRDE), em Santa Catarina, e como consultor na área de viabilidade de investimentos hoteleiros também em Santa Catarina.

Quando se decide implantar um hotel, deve-se cercar de uma série de cuidados para minimizar os riscos envolvidos. O empreendedor deve alicerçar sua decisão numa consistente pesquisa mercadológica, em que se analisa a situação atual e futura com a entrada deste novo empreendimento, e num estudo de viabilidade.

A seguir, na visão do autor, são apresentados alguns tópicos considerados relevantes num estudo para a implantação ou expansão de empreendimentos hoteleiros. A não observância ou o desconhecimento de alguns itens vêm causando sérias dificuldades para empreendedores e agentes financeiros que concedem financiamentos.

\section{Gênese de um Projeto}

A gênese de muitos hotéis estudados surgiu do fato de o empreendedor possuir um terreno, segundo ele, numa localização privilegiada e da concepção de que implantar um hotel é construir um prédio e mobiliá-lo, sem que ocorra, previamente, a definição da filosofia do empreendimento.

Em muitos casos faz-se contato com um profissional de engenharia ou arquitetura de quem se tem referências, e solicita-se a elaboração dos projetos de engenharia, sem atentar na experiência deste profissional na área hoteleira.

Não raro observa-se que empreendedores dessa área são oriundos de empresas de construção civil que estão buscando diversificar suas atividades. O projeto arquitetônico é alicerçado na experiência de construir edifícios com fins residenciais e em muitos casos não há consulta ao órgão representante da EMBRATUR.

Em alguns casos, constatou-se que os empreendedores solicitaram a classi frcação da EMBRATUR somente após o início da obra ou mesmo após a sua conclusão. Segundo pesquisa efetuada junto a SANTUR, órgão proposto da EMBRATUR em Santa Catarina, já ocorreram casos em que os empreendimentos deixaram de receber uma classificação superior a obtida, pela au sência de pequenos detalhes. $\mathrm{Na}$ fase de projeto esses detalhes seriam facilmente equacionados, mas as suas correções após a obra concluída, são onerosas e inviabilizam o ganho de mais uma estrela.

\footnotetext{
1. Bacharelem Engenharia Civil e Administraçāo pela Universidade Federal de Santa Catarina. Mestre em Engenharia de Produçāo pela Universidade Federal de Santa Catarina. Analista de projeto no Banco Regional de Desenvolvin End.: Rua Esteves Júnior, 545, apto. 1003 A - 88.015-530 - Florianópolis - SC- Brasil. Fax: (048) 221-8155.
} 


\section{Estudo de Mercado}

Em muitos dos casos analisados, no tocante ao estudo de mercado, o futur foi projetado a partir de um diagnóstico do passado considerando-se que este repetirse-ia no futuro, sem alterações substanciais. Falta neste caso uma visão estratégica, perante o que se sugere uma análise crítica utilizando-se as "Cinco Forças" de Porter(1991).

Um exemplo bem característicodeste viés foi a expansão nas ofertas de leitos voltados para o turismo de lazer que ocorreu no norte da ilha de Santa Catarina, Florianópolis (SC). Ocorreu grande expansão imobiliária e hoteleira, na década de 80 , baseada na demanda de argentinos pelas praias ali localizadas. Hoje existe um número significativo de hotéis e grande quantidade de residências secundárias, que também foram construídas buscando atender a essa demanda. A partir de 1994 o fluxo de turistas argentinos diminuiu e ficou a constatação que o grande atrativo não era a natureza e sim a taxa cambial que favorecia os platinos.

Segundo a SANTUR (1995), apenas cerca de $40 \%$ dos hotéis existentes no Brasil estão cadastrados na EMBRATUR, o que reduz a confiabilidade das estatísticas no setor hoteleiro. Considerando-se ainda que residências secundárias também são utilizadas por turistas e não são cadastradas na EMBRATUR, a confiabilidade nas estatísticas quanto à oferta dos meios de hospedagem é cada vez mais fragilizada.

\section{Taxa de Ocupaçāo e Índice de Freqüência}

A projeção de uma taxa de ocupação envolve alguns cuidados especiais, pois uma previsão enganosa pode viabilizar no papel um projeto, sem contudo garantir o sucesso do investimento.

Nos estudos de implantação, em muitos casos, não se encontrou um estudo de mercado consistente e como nem sempre existe disponibilidade de estatísticas confiáveis, os parâmetros apresentados no estudo de viabilidade do projeto devem ser checados pelo empreendedor e/ou pelo analista quanto a sua coerência.

Como aplicação do acima exposto, far-se-á uma averiguação expedita da taxa de ocupação de um hotel voltado ao turismo de negócios numa cidade do interior de Santa Catarina. Nesta cidade, os turistas de negócios, em sua quase totalidade, chegam nas segundas-feiras e retornam a sua cidade de origem, no mais tardar, às sextas-feiras. Conclui-se que a taxa de ocupação máxima não pode ser superior a $57 \%$, ou seja, o valor do percentual de 4 noites em um total de 7 noites semanais possíveis.

Por outro lado, não existe pesquisa em Santa Catarina e no Brasil que tenha a informação de quanto tempo um hotel leva para atingir o seu nível máximo da taxa de ocupação. Isto se mostra mais preocupante quando se considera o que será exposto nos próximos itens.
Quanto ao número médio de hóspede que ocupa cada UH (Unidade Habitacional), ou seja, o índice de frequiência, este número é influenciado pelo número médio de pessoas que é possível alojar nas UHs dos hotéis que estão sendo pesquisados. A maioria dos apartamentos podem hospedar até duas pessoas, mas existem UHs que alojam três ou mais pessoas, fato este que deverá ser observado na pesquisa.

\section{Viabilidade Econômica e Financiamento}

O Sistema BNDES, segundo as normas vigentes, apóia financeiramente até $80 \%$ do valor dos itens passíveis de financiamento, sendo então necessário que os empreendedores possuam a disponibilidade de $20 \%$, além de arcarem com os valores totais dos itens não passíveis de financiamento. Até meados do segundo semestre de 1996 o apoio financeiro era de até $65 \%$ e era concedido um prazo de até 6 meses de carência após a implantação do empreendimento. Era concedido um prazo total (carência mais amortização) de até 60 meses. A partir daquela data o prazo total foi aumentado para 96 meses.

Por outro lado, Rushmore (1985:118) observa que

Um hotel típico experimentará um crescimento lento na taxa de ocupação nos primeiros dois ou quatro anos de operação; em muitas situaçōes as receitas não cobrirão as despesas normais de operaçãoduranteesteperíodo. Oponto de equilibrio éatingido entre o segundo e o quinto ano de operação.

Infere-se que o prazos dos financiamentos, mesmo com a dilatação concedida, são inadequados para a atividade hoteleira e podem, em parte, explicar o alto nível de inadimplência do setor hoteleiro junto ao sistema financeiro.

Os empresários que receberam empréstimos do Sistema BNDES estão tentando alongar os prazos de seus financiamentos. Segundo Carlos Nascimento, diretor superintendente dos hotéis Transamérica, "financiar um investimento nas condições dos empréstimos do BNDES é arriscado". Ele considera ainda que "se o montante emprestado pela instituição superar um terço do total, o projeto torna-se inviável. O prazo de oito anos e as taxas de juros de aproximadamente $18 \%$ ao ano são os maiores empecilhos, mas não os únicos" (Gazeta Mercantil, 1998).

Na mesma reportagem, o consultor de empresas José Ernesto Marino Neto observa que muitos empreendedores, que conseguiram este tipo de financiamento, perceberam posteriormente que essa fonte era inadequada. Afirma ainda que "esse tipo de empréstimo deveria ter prazo mínimo de pagamento de 15 anos".

Segundo estudo da EMBRATUR (1998), no mercado internacional os financiamentos concedidos a hotéis possuem "prazos de amortização de 20 anos, ou mais, com juros de $8 \%$ ao ano". A indústria hoteleira nacional concorre em desvantagem "com o mercado internacional, tanto na captação de turistas internacionais quanto 
na de turistas brasileiros". O estudo conclui que se faz necessário promover alterações nas condições atuais dos financiamentos para o setor turístico.

A tomada de financiamento ou não é uma das mais importantes decisões sobre um investimento e se for inadequada pode acarretar grandes dificuldades não só para o empreendimento, mas também para os investidores e agentes financeiros envolvidos.

\section{Estimativa versus Orçamento}

Segundo Losso (1995), o conhecimento do custo de um plano de investimento é, sem dúvida, o ponto de partida para tomar-se a decisão de realizá-lo ou não, para a determinação do montante das inversões, para a definição de sua escala de produção e até mesmo para definição de suas especificações.

O empreendedor realiza estimativas de custos antes de executar os projetos definitivos. Ele necessita de informações probabilísticas confiáveis. O processo de tomada de decisão é alicerçado num conjunto de dados, tendo alguns mais importância do que outros. A confiabilidade está intimamente relacionada à qualidade desse conjunto de informações disponíveis.

A utilização de estimativas é útil nos estudos e nas análises, mas não deve substituir o orçamento.

Sugere-se, ainda, que os projetistas na elaboração dos orçamentos dêem mais atenção aos gastos com o andamento do projeto (treinamento e recrutamento de pessoal, comercialização pioneira, estoque inicial de produtos alimentares e de higiene, e outros gastos operacionais até atingir-se o ponto de equilíbrio), pois a não previsão desses gastos pode pôr em risco o sucesso do investimento já realizado, mesmo que fisicamente esteja implantado.

\section{Hotel Independente versus Hotel de Rede}

Mais de $90 \%$ dos empreendedores contatados pelo autor deste artigo não tiveram interesse ou mesmo nem chegaram a considerar a hipótese de filiar-se a uma rede hoteleira. Observa-se que todos esses empreendimentos estão localizados em Santa Catarina. Apresenta-se a seguir algumas considerações sobre o assunto.

Rede de hotéis é um grupo de três ou mais hotéis operados sob um nome comum, podendo os mesmos ser de propriedade da rede ou simplesmente ser administrados por ela (Rushmore, 1985).

Em algumas indústrias, o enfoque global é a única estratégia internacional possive porqueas vantagens da globalização só existemem determinado segmento, por exemplo, hotéis comerciais de preço elevado (Porter, 1991: 74).
Em Santa Catarinaexistem poucos hotéis de redes, contrariandoa tendência mundial. NoBrasilapenas 6\% do hotéis são administrados porcadeias internacionais.

Operam em Santa Catarina as redes Parthenon, Novotel, Ibis, Best Western e Le Canard. Esta última rede administra, até então, os hotéis de sua propriedade e é a única com sede em Santa Catarina.

Um hotel pode filiar-se a uma rede em sua fase de projeto ou mesmo posteriormente, quando estiver operando, desde que atenda aos requisitos necessários e considere vantajosa a sua inclusão na rede.

Com base na experiência das redes que operam nosEstados Unidos, Rushmore (1985) cita as seguintes vantagens para os proprietários que operam em rede sob o regime de franquia:

- Identificação imediata, reconhecimento e imagem: cada rede tem sua própria imagem, com indicação de preços, e mercado-alvo (familiar, férias, negócios, convenções);

- Central de reservas: as redes possuem central de reservas que permitem aos futuros hóspedes efetuar suas reservas através de ligações grátis. Um bom sistema de reservas garante uma ocupação de $15 \%$ a $30 \%$;

- Canal de divulgação e de vendas: ocorre maior divulgação e maior ação de vendas, em termos nacional e regional, que não poderiam ser arcados por um hotel independente;

- Procedimentos padronizados: as redes padronizam os procedimentos e periodicamente efetuam inspeções. Oferecem, também, treinamento a seus afiliados;

- Apoio gerencial: muitas redes oferecem assistência específica em vários aspectos do desenvolvimento do hotel e de administração, tais como na fase de projeto, de administração e de marketing. Esses serviços não estão cobertos pelo pagamento normal da franquia e são contratados separadamente;

- Compras de materiais em grupo: as redes, por exigirem padronização também nos móveis, nos utensílios, nos uniformes dos funcionários, nos materiais de higiene e de asseio oferecidos aos hóspedes, efetuam as compras em grupo, o que reduz o custo de aquisição, gerando ganhos aos seus participantes. franquia:

Por outro lado, Rushmore (1985) cita como ônus dos proprietários no caso da

- Requisitos físicos: muitas redes exigem um número mínimo de UHs, além da implantação de outras instalações. Aproximadamente três quartos dos hotéis dos EUA possuem piscinas por exigências das redes;

- Pagamento da taxa de administração: as redes exigem um pagamento inicial, de acordo com o porte da propriedade. Ao longo do período de operação há o pagamento de um percentual das vendas. Existe ainda o pagamentoda publicidade e do serviço de reservas. O custo da franquia varia de $2 \%$ a $7 \%$ das vendas das UHs. 
Os contratos variam de 10 a 25 anos;

- Exigência de padronização: são exigidos certos detalhes construtivos, de ope ração e de manutenção, sob pena de multa e/ou rompimento do contrato.

\section{Ciclo de Vida de um Hotel}

O ciclo de vida de um hotel relaciona os diversos estágios de um empreendimento com o crescimento de vendas. O seu conhecimento é importante para a determinação de um realista fluxo de caixa do empreendimento e, conseqüentemente, para o estudo da viabilidade e do retorno do capital investido. Segundo Porter (1991)

uma indústria atravessa quatro estágios: introdução, crescimento, maturidade e declinio Estes pontos são definidos por pontos de modulação no índice de crescimento das vendas da indústria.

Um hotel leva certo período de tempo para atingir o seu nível máximo de receita, conforme a Figura 1.

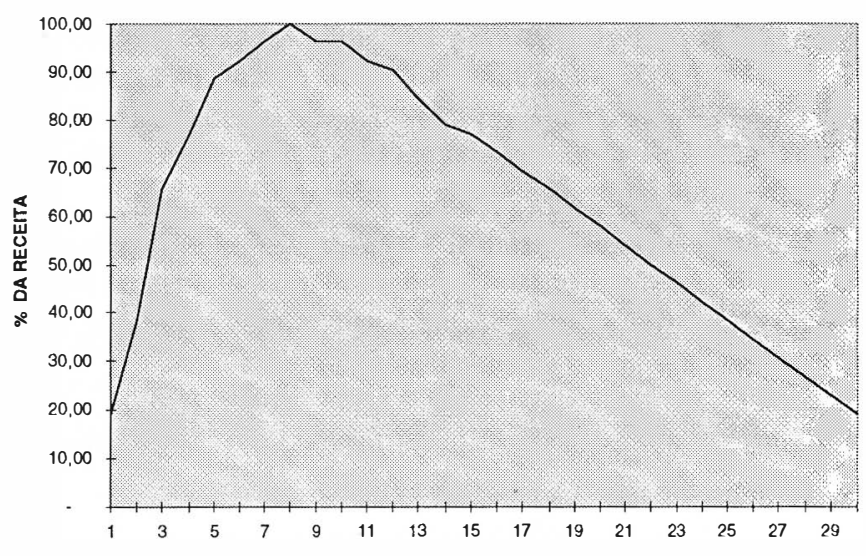

\section{FIGURA 1 - TIPICO CICLO DE VIDA: HOTEL ECONOMICO COM 200 UHs}

Fonte: Hospitality Valuation Service, Inc.( Rushmore,1985)

Segundo Rushmore (1985), em muitos casos o ponto de equilíbrio é atingido entre o segundo e o quinto ano após a implantação. Afirma, ainda, que a receita crescerá até o sétimo ou décimo ano, quando iniciará um declínio gradual decorrente dealguns fatores que poderão agir isoladamente ou em conjunto, a saber: depreciação física, depreciação funcional e obsolescência externa.

Como um exemplo de obsolescência externa, Rushmore (1985) cita a deterioração dos centros de algumas cidades e que alteram as condições de competitividade de um hotel na região. A obsolescência, por envolver questões macroeconômicas, nem sempre pode ser equacionada pelo empreendedor isoladamente e, neste caso, o ciclo de vida pode ser reduzido drasticamente.

O grau e a periodicidade com que é feita a reposição dos utensílios e do enxoval, assim como a manutenção e a remodernização das instalações, podem alterar o nível de competitividade de um hotel em seu ciclo normal de vida e conseqüentemente encurtá-lo ou alongá-lo.

\section{Conclusōes}

Neste artigo pretende-se chamar atenção do empreendedor e do projetista hoteleiro para alguns itens e fatos que ao não receberem a devida atenção na fase de projeto podem provocar graves conseqüências num empreendimento hoteleiro.

Constata-se, ainda, que no Brasil não existem linhas de crédito adequadas para a indústria hoteleira, em termos de prazos e de encargos financeiros, fato que explica, pelo menos em parte, o alto índice de inadimplência que o setor apresenta perante os agentes financeiros.

É importante realçar que se vive num mundo globalizado, em que a realidade independe de vontades particulares, e por isso qualquer investimento hoteleiro "concorre com o mundo".

\section{Referências Bibliográficas}

BELLI, Ari; HEINECK, Luiz Fernando M.; CAS AROTTO FILHO, Nelson.1996. Análise e avaliação de hotéis. Turism em Análise, São Paulo, v.7, n.2, p. 85-92, nov.

EMRATUR/GEPRON 1998 Financiamento à indústria do turismo - inadimplência - pleito da Associação Brasileira de Indústria de Hotéis - $A B I H$.

GAZETA MERCANTIL. 1998. Setor hoteleiro evita recursos do BNDES e quer prazo. São Paulo, 4 jun.

LOSSO, Iseu Reichman. 1995. Utilização das características geométricas da edificaf̧ão na elaborą̧ão de estimativas preliminares de custo: estudo de caso em uma empresa de construção. Florianópolis: Universidade Federal de Sant Catarina. (Dissertação de Mestrado em Engenharia Civil).

RTER, Michael E. 1991. Estratégias competitivas: técnicas para análise de indústrias e de concorrência. Rio de Janeiro: Campus.

IMMORE, Stephen. 1985. Hotels, motel and restaurants: evaluations and market studies. Chicago: American SANruR

padrôes de qualidade. Florianópolis: Santur.

\section{Recebido em 12/9/98
Aprovado em $12 / 10 / 98$}

